OPEN ACCESS

Edited by:

Reto Luder,

Zurich University of Teacher Education, Switzerland

Reviewed by: Ming Lui,

Hong Kong Baptist University, Hong Kong

Elizabeth Fraser Selkirk Hannah, University of Dundee, United Kingdom

*Correspondence: Zamira Hyseni Duraku zamira.hyseni@uni-pr.edu orcid.org/0000-0002-8268-3962

Specialty section

This article was submitted to Special Educational Needs, a section of the journal

Frontiers in Education

Received: 22 December 2020 Accepted: 06 April 2021 Published: 11 May 2021

Citation:

Hyseni Duraku Z, Jahiu G, Likaj Shllaku E, Boci L and Shtylla $H$ (2021) Albanian Preschool Personnel's Perceived Obstacles to Implementing Effective Inclusive Education. Front. Educ. 6:645254.

doi: 10.3389/feduc.2021.645254

\section{Albanian Preschool Personnel's Perceived Obstacles to Implementing Effective Inclusive Education}

\author{
Zamira Hyseni Duraku1*, Genta Jahiu'1 , Eglantina Likaj Shllaku², Loreta Boci² and \\ Hysnie Shtylla ${ }^{2}$
}

'Department of Psychology, University of Prishtina "Hasan Prishtina", Prishtina, Kosovo, ${ }^{2}$ Help the Life Association, Tirana, Albania

Access to high-quality early education promotes the academic success of children with disabilities; however, they are often overlooked in mainstream programs that lack essential support services. This study aimed to examine the obstacles to supporting inclusion and providing effective early education programs for children with disabilities in Albania as perceived by the preschool personnel. Preschool personnel $(n=107)$ working with children (3-6 years old) in the municipality of Tirana, in Albania, completed the survey. The obstacles to supporting children with disabilities were identified as lack of knowledge, supportive techniques, specific working tools, suitable facilities, and support staff, insufficient cooperation with parents, and inadequate educational programs for children with disabilities. The contextual factors and practical implications of the study, as well as future directions for research, are discussed in this article.

Keywords: early childhood education, disability, inclusion, high-quality programs, personnel, obstacles

\section{INTRODUCTION}

Early childhood is considered a critical period of growth and development that can influence outcomes throughout an individual's life (World Health Organization, 2007). Children's development relies on several interdependent domains of sensory-motor, cognitive, communication, and social-emotional function (Walker et al., 2011). Children's development is influenced by a wide range of biological and environmental factors, some of which protect and enhance development, while others compromise it (Fernald et al., 2009).

A crucial factor that is viewed as an important indicator for children's healthy development is the receipt of early education and participation in high-quality, inclusive preschool programs (Melhuish, 2011; Duncan and Magnuson, 2013).

The inclusive education approach creates opportunities for children with disabilities by ensuring that these students are given the opportunity to attend school with their peers in a supportive environment with resources and trained teachers. Inclusion is promoted internationally by both legislative mandate and societal values (Odom et al., 2003; Frankel and Gold, 2007). It is a practice in which early childhood educators are encouraged to create new opportunities for children with 
and without disabilities in mainstream early childhood education and care centers. Odom et al. (2004) acknowledged that the belief that children with disabilities should participate within natural environments alongside their peers without disabilities is a shared value for many early care and education programs worldwide.

Defining what constitutes a high-quality, inclusive early childhood education is considered to be complex (Love, 2018), yet there is agreement that in order to be deemed high-quality and inclusive, preschool programs must provide children with access to a wide range of learning opportunities, activities, settings, and environments, possibilities for participation or opportunities to engage, play, and learn with peers with and without disabilities, as well as adults, and support for the infrastructure of systems-level activities that undergird individuals and organizations (DEC and NAEYC Joint Position Statement, 2009). Furthermore, according to Barton and Smith (2015), the quality of preschool programs can be measured in three different dimensions: (1) access to learning opportunities (e.g., the provision of materials that can be used by children with or without disabilities); (2) active participation in learning, assisted by adults using individualized practices; and (3) supports that provide adults (teachers and parents) the resources needed to help children learn. Additionally, according to Camilli et al. (2010), the quality of inclusive preschool programs is usually measured based on seven dimensions: program goals and purposes; staff support and perceptions; accessibility and adequacy of the physical environment; individualization; children's participation and engagement; adult-child contacts and relationships; and childchild contacts and interactions.

Developed nations, such as Canada, the United States, Australia, Sweden, and Italy, are making significant progress by working on the inclusion of preschool children into typical early childhood programs (Palsha, 2002; Frankel, 2004). However, it has yet to gain momentum in other countries. Fewer than $10 \%$ of countries have laws that ensure full inclusion in education, according to the United Nations Educational, Scientific and Cultural Organization's [UNESCO's] 2020 Global Education Monitoring Report: Inclusion and education-All means all. The report identifies an exacerbation of exclusion during the COVID-19 pandemic and estimates that about $40 \%$ of lower- and middle-income countries have not supported disadvantaged learners during temporary school shutdown. It notes that 258 million children and youth were entirely excluded from education, with poverty as the main obstacle to access. Children with disabilities are 2.5 times more likely to never go to school, according to the Global Education Monitoring Report: Inclusion and Education (UNESCO, 2020). Later in life, they are more likely to experience poverty.

Around 250 million children under 5 years of age in lowerand middle-income countries are at risk of not reaching their developmental potential (Black et al., 2017). Furthermore, based on another study in 195 countries and territories, 52.9 million children under 5 years of age have developmental disabilities. Of these, $95 \%$ live in lower- and middle-income countries (Olusanya et al., 2018).
Furthermore, while global attention has been given to the need for improving the quality of early education practices and increasing inclusiveness for diverse learners (Wesley and Buysse, 2010; Peisner-Feinberg et al., 2011), limited progress has been made in increasing the placements of children with disabilities in inclusive settings (Warren et al., 2016). Therefore, young children with disabilities are often overlooked in mainstream programs and lack services designed to ensure their development (Simeonsson, 2000).

High-quality preschool programs have been shown to have lasting positive effects for all children. That quality is considered especially beneficial for children with disabilities, as early childhood is a critical time for the implementation of early interventions to help young children with disabilities reach their full potential (Karoly et al., 2006). Thus, active participation in preschool programs that provide developmentally appropriate and supportive environments is particularly crucial for young children with disabilities (United Nations Educational, Scientific and Cultural Organization, 2009).

The quality of preschool programs, particularly those that provide an inclusive environment for children with disabilities, has also been consistently shown to be influenced by several factors. For instance, it has been demonstrated to be dependent on the extent of teachers' professional development (Early et al., 2007). Early childhood researchers have recommended that both in-service and pre-service professional development be expanded in order to bridges the gap between research and practice and to contribute to the placement of effective teachers in inclusive classrooms (Chang et al., 2005; Snyder et al., 2015).

Family involvement in children's education throughout childhood is also essential for children with disabilities, especially during the early years (World Health Organization and The United Nations Children's Fund, 2012).

Families are the first and most powerful influence on children's early learning and development. Parents are considered vital in many aspects of the educational settings and child development; they can contribute to the development of individual education plans, and they can provide information on the child's strengths and weaknesses at home, background information, child history, development, and any family factors that may affect child learning (Elbaum et al., 2016). Moreover, children benefit from the development of positive and supportive relationships between early childhood programs and their families (Weiss et al., 2006).

\section{Current Challenges of Inclusion in Early Childhood Education in Albania for Children With Disabilities}

Education in Albania is compulsory until the age of 16 . The current regulatory framework regarding children in Albania is well developed. The Law Nr. 69 of 2012 "On Pre-university education" regulates pre-university education in Albania and calls for free and mandatory education. In general, the Albanian legal framework establishes the right to a free public education for every child, regardless of his or her needs and special abilities, declaring: "The 
inclusion of children with disabilities in special educational institutions is temporary. The inclusion of children with disabilities in mainstream schools should be a priority," said the UNICEF report.

Yet, improving the quality of the early education system in Albania is viewed as a current challenge for the country (Fuller, 2017). While the number of children enrolled in pre-primary education (5-6 years old) has increased in recent years such that they account for $81 \%$ of Albanian preschool-aged children, the gross enrollment of children aged 3-6 remains lower than this rate (Mingat and Hoxha, 2010).

In Albania, inclusive education has not been a natural evolution of previous experiences or a necessity, according the UNICEF report "Facing the challenges of inclusive education in Albania." The report highlights that, in contrast to other western societies, in which inclusive education is a product of people with disabilities, their parents, and practitioners, in Albania, international influence and imitation have been the main factors contributing to this development. All the major changes have happened through administrative activities rather than as a result of lobbying and pressure from people directly or indirectly involved in the process. Presently, inclusive education reflects the aims and realities of its implementation in Albanian education institutions. The findings of the reports also acknowledged the lack of reliable data in relation to children with disabilities. There are an estimated 120,000 children with some form of disability in Albania. In 2012, the ex-Minister of Education and Science unofficially reported 2,123 Children With Disability (CWD) enrolled in basic education, of whom 736 attend special schools. According to the ex-Minister of Education and Sport of Albania, the official drop-out rate for CWD was high, at $7 \%$.

A variety of practical issues hinder the participation of CWD and children from vulnerable groups in basic and secondary education, including teachers' limited training on disability issues, lack of assistant teachers in overcrowded classrooms, poor infrastructure, lack of proper transportation, and discrimination and bullying from older children, school staff, and parents of other children. Poor cooperation between professionals of different disciplines and between different sectors of local government and the lack of teaching materials and adjusted school programs for CWD remain hurdles for CWD to realize their right to education.

Even though the principle of inclusive education is widely accepted in education institutions and legislation, its implementation faces many barriers. The transformation of schools into inclusive environments calls for multi-planning activities, and it is a process that depends on society's support, curriculum reform, schools' organization, teacher training, and the provision of supportive, specialized services.

According to Save the Children (2012), the world's first international charity for children, active in over 100 countries, the enrollment and inclusion of children with disabilities in the preschool and compulsory education system remains a concern in Albania. Save the Children has worked in Albania since 1999. The organization's humanitarian work in the country focuses on reducing the impact of disasters for children and their communities and developing plans of action that ensure effective responses in coordination with other agencies. Based on the latest data of Albania's State Social Service, the estimated number of children with disabilities between zero and 6 years old in Albania is 4,776 (Save the Children, 2012). However, this data only represents those who receive disability allowances, meaning children with moderate or severe disabilities (Fuller, 2017). Moreover, families are only entitled to these allowances for one child, indicating that the number of children with disabilities is actually higher than what is currently being reported (Tahsini et al., 2014).

Furthermore, Save the Children noted that while assistant teachers could facilitate inclusion, there remains a great, unfulfilled need for these assistants at the preschool level and beyond (Tahsini et al., 2014). Significant progress has been made in improving the quality of preschool institutions in Albania, but the quality of staff-their level of training and knowledgeremains inadequate (Fuller, 2017). While most teachers hold higher education degrees (Mingat and Hoxha, 2010), many lack knowledge and skills regarding inclusive practices and are unprepared to design and implement individualized education plans for children with disabilities (Tahsini et al., 2014). According to the 2010 ETF country report for Albania, both pre-service and in-service teachers are not yet ready to respond to diversity in the class. The teacher training curriculum currently lacks emphasis on teacher competences pertinent to the development of inclusive education practices.

Therefore, if children with disabilities and their families are not provided with timely and appropriate early intervention, support, and protection, children's developmental and educational difficulties can become more severe, often leading to long-term consequences, including increased likelihood of living in poverty and profound exclusion from broader society.

The current study aims to examine the obstacles to supporting inclusion and providing effective early education programs for children with disabilities in Albania as perceived by preschool personnel. The perceptions of preschool personnel can serve as a valuable source in the evaluation of the quality of inclusive programs. Therefore, these findings can serve as a baseline for further studies, and they also have implications for future efforts aimed at evaluating and improving the quality of inclusive programming.

\section{MATERIALS AND METHODS}

\section{Sample and Procedure}

This study utilized convenience sampling, ensuring that the sample would reflect the proportions of specific roles of education professionals (such as heads of preschool programs, teachers of 3-6 year-old children, assistant teachers, physicians, and psychologists) within participating institutions. Participants were preschool staff selected to be part of the Help the Life Association project "Early Intervention, the Best Approach 
to Advance Child Development" conducted with the public preschool staff of the Tirana municipality. The Help the Life Association is an Albanian NGO working since 1998 to promote the rights and wellbeing of children and youths with disabilities in Albania by advancing the professional capacities of early educational settings in Albania, strengthening the quality of support, development, and education of all children, including children with disabilities during their early stages of development. Prior to completing the survey, approval from the Center of Economic Development and Education of Children for recruiting participants was obtained. Participants were selected randomly from the lists of employees provided to the Help the Life Association by the Center of Economic Development and Education of Children. The invitations were sent via email along with the questionnaire in a Google form. Participation was voluntary, and participants were informed that their responses would remain confidential and that they could revoke their participation at any time. The survey data were collected in March 2019, and the authors of this research received help from the association project staff and external experts who were engaged in the research.

A total of 107 preschool staff, $98.1 \%$ of whom were women, participated in the current study. Of these, $97.2 \%$ were over 30 years old at the time of the study. Approximately $80 \%$ of the participants were educators of children aged 3-6 years, about $5 \%$ were assistant teachers, about $4 \%$ were the heads of the preschool programs, and the remainder were physicians and psychologists. More than $77 \%$ of participants had more than 5 years of experience working with children of this age group; $13 \%$ had no experience in working with children with development disabilities, $63 \%$ had sporadic experience, and $24 \%$ had adequate experience. The demographic characteristics of the final sample are shown in Table 1.

\section{Measuring Instruments}

The authors developed the questionnaire used in this study to examine the obstacles in the way of inclusive education for children with disabilities in Albania. The questionnaire included key features of high-quality and inclusive education programs

TABLE 1 | General descriptions of the sample $(N=107)$.

\begin{tabular}{lcc}
\hline Variable & $\boldsymbol{n}$ & $\%$ \\
\hline Gender & 105 & \\
Female & 2 & 98.1 \\
Male & & 1.9 \\
Age of personnel & 3 & \\
20-30 years old & 104 & 2.8 \\
>30 years old & & 97.2 \\
Role in the preschool program & 4 & \\
Head & 85 & 3.7 \\
Teachers (3-6 year-old children) & 5 & 79.4 \\
Assistant teachers & 7 & 4.7 \\
Physician & 6 & 6.5 \\
Psychologist & & 5.6
\end{tabular}

and the factors that had previously impacted the inclusion of and support for children with disabilities in early childhood settings as potential obstacles (DEC and NAEYC Joint Position Statement, 2009; Barton and Smith, 2015; Love, 2018).

Participants were asked to rate, on a scale from 1 (not at all) to 5 (very much), the extent to which the institutions in which they worked offered opportunities for the inclusion of children with disabilities aged 3-6. Participants were asked to indicate who, among the staff, provided additional support for children with disabilities within their preschool programs-the support staff, the preschool psychologist, or the regular preschool class teachers. Furthermore, the participants were asked to select and rate, on a scale from 1 (not at all) to 5 (very much), a list of the obstacles they face while working with children with disabilities. The potential obstacles identified in the survey included lack of support staff, lack of parental cooperation, lack of professional development in working with children with disabilities, lack of specific equipment and tools, and lack of learning materials.

Participants' ( $n=107$ ) demographic characteristics (gender, age, year of experience) and information regarding their role in the preschool program were also collected as part of the questionnaire.

\section{Analysis}

Absolute numbers and respective percentages were used to describe the distribution of participants according to various categorical variables. Besides reporting absolute numbers and respective percentages, we used several other measures for describing and assessing variables.

Mean values and standard deviations were calculated for continuous (scale) variables, with the 5-point Likert scale variables being considered as discrete numerical variables ranging from 1 to 5. The Fisher-Freeman-Halton's test was used to identify significant differences among categorical variables due to the small sample and zero frequencies in numerous table cells. The general linear model procedure (Tamhane's T2 test) was used to check the statistical significance of the associations between continuous (scale) and categorical variables. In all cases, a relationship was considered statistically significant if $p<0.05$. All the statistical analyses were carried out using IBM SPSS Statistics, version 22.

\section{RESULTS}

About two thirds of the participants declared their institution moderately supportive $(n=36 ; 33.6 \%)$ or very supportive ( $n=33 ; 30.8 \%)$ of the comprehensive inclusion of children with disabilities. The average institutional support was 3.7 $(S D=1.2)$. Their responses are summarized in Table 2 . The results indicate that a large proportion (64.4\%) is aware of inclusive education, implying that more than one third still needs to be sensitized about the importance and relevance of inclusive education in the lives of children with disabilities. 
TABLE 2 | Preschool personnel perceptions regarding their institution offering opportunities for inclusion of children with disabilities aged 3-6 years (responses from a total of 107 preschool personnel).

\begin{tabular}{llc}
\hline Mean institutional support for inclusiveness (SD) & \multicolumn{2}{l}{$\mathbf{3 . 7 0}$ (SD = 1.23) } \\
\hline Variable & $\boldsymbol{n}$ & $\%$ \\
\hline Level of opportunities for inclusion & & \\
None & 9 & 8.4 \\
Little & 9 & 8.4 \\
Moderate & 20 & 18.7 \\
Many & 36 & 33.6 \\
Extremely & 33 & 30.8 \\
\hline
\end{tabular}

SD, standard deviation.

\section{Type of Support Provided by Participants' Roles in Preschool Programs}

Table 3 presents the distribution level and by whom additional support is provided to children with disabilities by role at the respective institution.

It can be observed that the differences are not statistically significant $(p>0.05)$; however, despite the lack of statistical significance, the data suggest that higher proportions of program executives (75\%) and psychologists (67\%) think that support for children with disabilities is provided by the institution's psychologist, while educators (43\%), support educators (40\%), and physicians $(43 \%)$ were more likely to state that no special support was provided for children with disabilities.

\section{Obstacles to Supporting Children With Disabilities}

Participants were asked to rate several factors as potential barriers in their work to provide maximal support to children with disabilities. The primary obstacle that was identified was "lack of specific working tools and suitable facilities" $\left(M=3.61, S D=1.46^{*}\right)$, followed by "lack of support staff" $\left(M=3.44, S D=1.42^{*}\right)$, "lack of sufficient cooperation with parents" $\left(M=3.38, S D=1.35^{*}\right)$, "lack of knowledge and supportive techniques" $\left(M=3.33, S D=1.35^{*}\right)$, and "inadequacy of educational programs for the specifics of children with disabilities" $\left(M=3.23, S D=1.39^{*}\right)$. About half of all participants estimated that each of the listed factors negatively affected the provision of maximum levels of support for children with disabilities either relatively or very much. Their responses are summarized in Table 4.

\section{Level of Obstacles by Role in Program}

Table 5 presents the mean value of the perceived obstacles by the role that participants hold in the preschool programs. Assistant teachers and teachers rated the lack of support staff as a significantly lower barrier ( $M=1.40$ and $M=3.41$, respectively) than did the other groups. Physicians rated the lack of sufficient cooperation with parents as a significantly greater obstacle ( $M=4.14)$ compared to other groups. Supportive educators considered the lack of specific work tools and appropriate facilities a significantly lower obstacle $(M=1.20)$ compared to other groups.

\section{DISCUSSION AND PRACTICAL IMPLICATIONS}

The present study investigated the obstacles to supporting inclusion and providing effective early education programs for children with disabilities in Albania as perceived by preschool personnel.

The current study results indicate that preschool programs lack specific tools (learning materials) and suitable facilities for working with children with disabilities, support education/staff, adequate cooperation with parents, and knowledge and supportive techniques, as well as having inadequate educational programs for children with disabilities. Therefore, they demonstrate the need to improve the level of support for children with disabilities in the early education system by making appropriate interventions to create high-quality learning experiences and inclusive classrooms (Odom et al., 2011).

The field of early education and child development has stressed the concept that all children and families have universal needs that are shared by children with disabilities and their families (Hastings and Taunt, 2002). Moreover, the broader community benefits by supporting the needs of all children and their families. Therefore, identifying ways to meet these shared needs should be a focus for policy, funding, and planning in early childhood services (McLoughlin and Stonehouse, 2006;

TABLE 3 | Relationship (chi square test) between type of support for children with disabilities and role in preschool program (responses from a total of 107 preschool personnel).

\begin{tabular}{|c|c|c|c|c|c|c|}
\hline \multirow[t]{2}{*}{ Variable } & \multicolumn{5}{|c|}{ Role in Program } & \multirow[t]{2}{*}{$p$-value } \\
\hline & Head & Teacher & Assistant Teacher & Physician & Psychologist & \\
\hline \multicolumn{7}{|l|}{ Type of support } \\
\hline By the psychologist & $3(75)$ & $47(55)$ & $3(60)$ & $4(57)$ & $4(67)$ & $0.140^{\star}$ \\
\hline By assistant teachers & $0(0)$ & $2(2)$ & $0(0)$ & $0(0)$ & $1(17)$ & \\
\hline By teachers and psychologist & $0(0)$ & $0(0)$ & $0(0)$ & $0(0)$ & $1(16)$ & \\
\hline No special support & $1(25)$ & $36(43)$ & $2(40)$ & $3(43)$ & $0(0)$ & \\
\hline
\end{tabular}

Absolute number and column percentage (in parentheses). * $p$-value according to the Fisher-Freeman-Halton's test. 
Moore, 2008). Quality cooperation between educational institutions and parents has been documented as essential for healthy development in all children (Dahlberg et al., 1999). Existing research has shown that parent training programs can improve parent stress, well-being, mental health, and self-efficacy, as well as the quality of parent-child interactions (Barlow et al., 2014).

In Albania, preschool programs need to provide a range of services and support to ensure and enhance children's development (Werner, 2000), strengthen family competencies, and promote the social inclusion of families and children (Meijer et al., 2007). Funding for early care and education for children with disabilities should be primarily reserved for participation in inclusive classrooms to help ensure adequate availability across geographic areas, as well as appropriate levels of staffing, services, environmental supports, and professional development in these programs (Lawrence et al., 2016).

Furthermore, specialized services for family-focused support, along with service planning and coordination, as well as assistance and support in accessing mainstream services, such as preschool and childcare, are needed for children with disabilities and their families. Albanian preschool programs should be further adapted to create inclusive settings in which children with disabilities are offered a vital space to support their optimal development through child-focused learning, play, participation, peer interaction, and the development of friendships (Kelly et al., 2012). In addition, staff members in early childhood settings should review their curricula and pedagogy to ensure they align with program standards and reflect inclusion (Buysse and Hollingsworth, 2009).

Public preschools should also focus on strengthening their personnel capacities and offering ongoing support to build and sustain capacity with respect to diversity, equity, and inclusion. The presence of additional staff beyond the typical staffing ratio as needed to support inclusion, as well as technical support and consultation, specialized equipment and materials, and effective communication with parents are all essential (Klingner et al., 2013).

Moreover, early childhood interventions and allied services should form an essential part of the services for young children with disabilities (Singer et al., 2007). Early childhood practitioners with specific expertise in building and supporting programmatic capacity might be needed to promote inclusion, and programs might also require additional technical support and consultations or specialized equipment and materials (Edwards, 2005). Taken together, these findings can serve as a baseline for further studies. They also have implications for future efforts aimed at evaluating and improving the quality of inclusive programming.

For children in inclusion programs, every effort needs to be made to ensure that the program quality is acceptable and that appropriate levels of services are provided, as a lack of necessary supports and services would deprive not only the child with a disability, but also the rest of the class (Rafferty and Griffin, 2005). While training for overall inclusion is essential, ongoing differentiated and specific training that focuses on effectively dealing with different disabilities is crucial (Brownell
TABLE 4 | Potential obstacles to maximally supporting children with disabilities (responses from a total of 107 preschool personnel).

\begin{tabular}{|c|c|c|}
\hline Potential barrier factor & Absolute $n$ & $\%$ \\
\hline \multicolumn{3}{|c|}{$\begin{array}{l}\text { Lack of specific working tools and suitable } \\
\text { facilities }\left(M=3.61 ; S D=1.46^{\star}\right)\end{array}$} \\
\hline Not at all & 11 & 10.3 \\
\hline Little & 21 & 19.6 \\
\hline Average & 14 & 13.1 \\
\hline Relatively significant & 14 & 13.1 \\
\hline Significant barrier & 47 & 43.9 \\
\hline \multicolumn{3}{|c|}{ Lack of support staff $\left(M=3.44 ; S D=1.42^{\star}\right)$} \\
\hline Not at all & 11 & 10.3 \\
\hline Little & 22 & 20.6 \\
\hline Average & 21 & 19.6 \\
\hline Relatively significant & 15 & 14.0 \\
\hline Significant barrier & 38 & 35.5 \\
\hline \multicolumn{3}{|c|}{$\begin{array}{l}\text { Lack of sufficient cooperation with parents } \\
\left(M=3.38 ; S D=1.35^{\star}\right)\end{array}$} \\
\hline Not at all & 13 & 12.1 \\
\hline Little & 14 & 13.1 \\
\hline Average & 30 & 28.0 \\
\hline Relatively significant & 19 & 17.8 \\
\hline Significant barrier & 31 & 29.0 \\
\hline \multicolumn{3}{|c|}{$\begin{array}{l}\text { Lack of knowledge and supportive techniques for } \\
\text { capacity building of children with disabilities } \\
\left(M=3.33 ; S D=1.35^{\star}\right)\end{array}$} \\
\hline Not at all & 10 & 9.3 \\
\hline Little & 25 & 23.4 \\
\hline Average & 22 & 20.6 \\
\hline Relatively significant & 20 & 18.7 \\
\hline Significant barrier & 30 & 28.0 \\
\hline
\end{tabular}

Inadequacy of educational programs for the specifics of children with disabilities $(M=3.23$; $\left.S D=1.39^{\star}\right)$

Not at all

12.1

Little

Average

Relatively significant

22.4

24.3

Significant barrier

12.1

29.0

$M=$ mean; $S D=$ standard deviation .

et al., 2005). In particular, administrators should attend inservice training sessions provided to teachers and other staff. Provisions must be made for the ongoing re-evaluation of the specific arrangements for inclusion, such as the examination of placement decisions, class size and composition, support systems for both regular and special education personnel, and child outcomes. Furthermore, without effective administrators to address these issues, teachers are left in the untenable situation of having significant responsibility for the success of inclusion without the specific authority to change particular details to ensure that success.

\section{Limitations and Future Directions}

Several limitations of the current study have to be acknowledged and should be considered when evaluating these findings. 
TABLE 5 | The associations (Tamhane's T2 test) between barrier factors and the role that participants play at the institution; mean values from the general linear model (responses from a total of 107 child education professionals).

\begin{tabular}{llllll}
\hline \multirow{3}{*}{ Barrier factors } & & \multicolumn{2}{c}{$95 \% \mathrm{Cl}$} \\
\cline { 3 - 3 } & Mean & Lower & Upper & $p$-value \\
& value & limit & limit & \\
\hline
\end{tabular}

\begin{tabular}{|c|c|c|c|c|}
\hline \multicolumn{5}{|l|}{ Role in program } \\
\hline Head & 4.00 & 2.16 & 5.84 & 1.000 \\
\hline Teacher (children aged 3-6 years) & 3.65 & 3.33 & 3.96 & 1.000 \\
\hline Assistant teachers & 1.20 & 0.64 & 1.76 & 0.011 \\
\hline Physician & 4.57 & 3.84 & 5.30 & 0.696 \\
\hline Psychologist & 3.67 & 2.58 & 4.75 & $\begin{array}{c}\text { Reference } \\
\text { group }\end{array}$ \\
\hline
\end{tabular}

$\begin{array}{lcccc}\begin{array}{l}\text { Lack of support staff } \\ \text { Role in program }\end{array} & & & & \\ \text { Head } & 4.00 & 2.16 & 5.84 & 0.998 \\ \text { Teachers (children aged 3-6 years) } & 3.41 & 3.11 & 3.72 & \mathbf{0 . 0 2 1} \\ \text { Assistant teachers } & 1.40 & 0.72 & 2.08 & <\mathbf{0 . 0 0 1} \\ \text { Physician } & 4.00 & 3.08 & 4.92 & 0.964 \\ \text { Psychologist } & 4.50 & 3.93 & 5.07 & \text { Reference } \\ & & & & \text { group }\end{array}$

Lack of sufficient cooperation with parents

Role in program

$\begin{array}{llllc}\text { Head } & 3.75 & 2.23 & 5.27 & 0.558 \\ \text { Teachers (children aged 3-6 years) } & 3.36 & 3.06 & 3.67 & 0.422 \\ \text { Assistant Teachers } & 3.40 & 2.29 & 4.51 & 0.733 \\ \text { Physician } & 4.14 & 3.50 & 4.78 & \mathbf{0 . 0 3 5} \\ \text { Psychologist } & 2.50 & 1.62 & 3.38 & \text { Reference } \\ & & & & \text { group }\end{array}$

Lack of knowledge and supportive techniques for capacity building of children with disabilities

Role in program

$\begin{array}{lllll}\text { Head } & 3.75 & 1.36 & 6.14 & 0.754 \\ \text { Teachers (children aged 3-6 years) } & 3.36 & 3.12 & 3.68 & 0.392 \\ \text { Assistant teachers } & 3.40 & 0.76 & 2.84 & 1.000 \\ \text { Physician } & 4.14 & 3.26 & 5.31 & 0.069 \\ \text { Psychologist } & 2.50 & 0.94 & 3.39 & \text { Reference } \\ & & & & \text { group }\end{array}$

Inadequacy of educational programs for the specifics of children with disabilities

Role in program

$\begin{array}{lllll}\text { Head } & 3.25 & 1.25 & 5.25 & 0.998 \\ \text { Teachers (children aged 3-6 years) } & 3.32 & 3.02 & 3.62 & 0.884 \\ \text { Assistant teachers } & 1.60 & 0.92 & 2.28 & 0.466 \\ \text { Physician } & 3.86 & 2.50 & 5.21 & 0.708 \\ \text { Psychologist } & 2.67 & 1.58 & 3.75 & \text { Reference } \\ & & & & \text { group }\end{array}$

Statistically significant $(p<0.05)$.

While the findings represent the current level of inclusion and obstacles to increased inclusion as a means to encourage inclusive practices for Albanian children, they only indicate the current situation in the main municipality of Albania and cannot be generalized to all Albanian preschool programs. Another limitation concerns the inability to examine variations in outcomes associated with specific subgroups within the population of children with disabilities, as defined by the type of disability, family characteristics, or environmental risks due to both the lack of information about these characteristics and the small sample size. Moreover, further research that examines strategies for the effective implementation of preschool inclusion (e.g., awareness creation, teacher development) and the extent of communication between educators and parents is needed to further analyze the obstacles to inclusion and to improve practical recommendations (Staples and Diliberto, 2010). Further research should be conducted to evaluate the effectiveness of different teaching models, course organizations, and cooperation between staff in preschool institutions (e.g., heads of institutions, educators, psychologists, physicians). This will assist in the promotion of high-quality inclusion efforts, as well as in the creation of strategies to best develop competent personnel who can meet the diverse needs of all children. In this regard, the use of open-ended questions would also contribute to capturing additional relevant elements that could be used to explain the current findings and guide future interventions.

Moreover, evaluating teachers' attitudes toward inclusion in preschool education could help identify areas in which teachers need additional support and could help educators implement effective and successful inclusion programs (Taylor et al., 1997). Thus, continued collaboration and consultation across all levels of the education system, including families, teachers, social service agencies, psychologists, and policymakers, is essential to promote creative and successful solutions for early childhood inclusion (Frankel, 2004).

\section{DATA AVAILABILITY STATEMENT}

The datasets generated during and/or analyzed during the current study are available from the corresponding author on reasonable request.

\section{ETHICS STATEMENT}

The studies involving human participants were reviewed and approved by the University of Pristine, Faculty of Philosophy Ethical Committee. The patients/participants provided their written informed consent to participate in this study.

\section{AUTHOR CONTRIBUTIONS}

The research idea, has been developed by ZHD who has also contributed in all parts of the manuscript development and finalization. Each of other contributing authors have been involved in data gathering, analyzing, literature review, and manuscript development from the initial phases to the finalization of it. All authors contributed to the article and approved the submitted version. 


\section{FUNDING}

This work was supported by the Help the Life Association as part of the project "Early Intervention, the Best Approach to Advance Child Development," supported by a grant from the Civil Society Programme for Albania and Kosovo, financed by

\section{REFERENCES}

Barlow, J., Smailagic, N., Huband, N., Roloff, V., and Bennett, C. (2014). Group-based parent training programmes for improving parental psychosocial health. Cochrane Database Syst. Rev. 2014:CD00202. doi: 10.1002/14651858. CD002020.pub4

Barton, E. E., and Smith, B. J. (2015). Advancing high-quality preschool inclusion: a discussion and recommendations for the field. Topics Early Childhood Special Educ. 35, 69-78. doi: 10.1177/0271121415583048

Black, M. M., Walker, S. P., Fernald, L. C. H., Andersen, C. T., DiGirolamo, A. M., Lu, C., et al. (2017). Advancing early childhood development: from science to scale: early childhood development coming of age: science through the life course. Lancet 389, 77-90. doi: 10.1016/S0140-6736(16)31389-7

Brownell, M. T., Ross, D. D., Colón, E. P., and McCallum, C. L. (2005). Critical features of special education teacher preparation: a comparison with general teacher education. J. Special Educ. 38, 242-252. doi: 10.1177/ 00224669050380040601

Buysse, V., and Hollingsworth, H. L. (2009). Program quality and early childhood inclusion: recommendations for professional development. Topics Early Childhood Special Educ. 29, 119-128. doi: 10.1177/0271121409332233

Camilli, G., Vargas, S., Ryan, S., and Barnett, W. S. (2010). Meta-analysis of the effects of early education interventions on cognitive and social development. Teach. Coll. Rec. 112, 579-620.

Chang, F., Early, D. M., and Winton, P. J. (2005). Early childhood teacher preparation in special education at 2-and 4-year institutions of higher education. J. Early Interv. 27, 110-124. doi: 10.1177/105381510502700206

Dahlberg, G., Moss, P., and Pence, A. R. (1999). Beyond Quality in Early Childhood Education and Care: Postmodern Perspectives. DEC/NAEYC. (2009). Early Childhood Inclusion: A Joint Position Statement of the Division for Early Childhood (DEC) and the National Association for the Education of Young Children (NAEYC). Chapel Hill: The University of North Carolina, FPG Child Development Institute.

DEC and NAEYC Joint Position Statement (2009). Early Childhood Inclusion: A Joint Position Statement of the Division for Early Childhood (DEC) and the National Association for the Education of Young Children (NAEYC). Chapel Hill: The University of North Carolina, FPG Child Development Institute.

Duncan, G. J., and Magnuson, K. (2013). Investing in preschool programs. J. Econ. Perspect. 27, 109-132. doi: 10.1257/jep.27.2.109

Early, D. M., Maxwell, K. L., Burchinal, M., Alva, S., Bender, R. H., Bryant, D., et al. (2007). Teachers' education, classroom quality, and young children's academic skills: results from seven studies of preschool programs. Child Dev. 78, 558-580. doi: 10.1111/j.1467-8624.2007.01014.x

Edwards, A. (2005). Relational agency: learning to be a resourceful practitioner. Int. J. Educ. Res. 43, 168-182. doi: 10.1016/j.ijer.2006.06.010

Elbaum, B., Blatz, E. T., and Rodriguez, R. J. (2016). Parents' experiences as predictors of state accountability measures of schools' facilitation of parent involvement. Remedial Special Educ. 37, 15-27. doi: 10.1177/ 0741932515581494

Fernald, L. C., Kariger, P., Engle, P., and Raikes, A. (2009). Examining Early Child Development in Low-Income Countries: A Toolkit for the Assessment of Children in the First Five Years of Life. Washington, D.C: World Bank, doi: 10.1596/28107

Frankel, E. B. (2004). Supporting inclusive care and education for young children with special needs and their families: an international perspective. Childhood Education 80, 310-316. doi: 10.1080/00094056.2004.10521277

Frankel, E. B., and Gold, S. (2007). "Principles and practices of early intervention", in A Comprehensive Guide to Intellectual and Developmental Disabilities, eds I. Brown, and M. Percy (Baltimore, MD: Paul H. Brookes Publishing Co.), $451-466$. the Norwegian Ministry of Foreign Affairs, and managed by the Kosovar Civil Society Foundation (KCSF) in partnership with Partners Albania for Change and Development (PA). The content and recommendations do not represent the official position of the Norwegian Ministry of Foreign Affairs and Partners Albania for Change and Development (PA) (Grant No. NOR-05).

Fuller, S. (2017). Early Childhood Education in Albania at a Glance Subsector Review Final. Available online at: https://www.academia.edu/35872803/ Early_Childhood_Education_in_Albania_A_Subsector_Review (accessed November 2020).

Hastings, R. P., and Taunt, H. M. (2002). Positive perceptions in families of children with developmental disabilities. Am. J. Ment. Retard. 107, 116-127. doi: 10.1352/0895-801720021072.0.CO;2

Karoly, L. A., Kilburn, M. R., and Cannon, J. S. (2006). Early Childhood Interventions: Proven Results, Future Promise. Santa Monica, CA: Rand Corporation.

Kelly, A., Ghalaieny, T., and Devitt, C. (2012). A pilot study of early intervention for families with children with or at risk of an intellectual disability in northern Malawi. J. Policy Pract. Intellect. Disabil. 9, 195-205. doi: 10.1111/j.1741-1130. 2012.00354.x

Klingner, J. K., Boardman, A. G., and McMaster, K. L. (2013). What does it take to scale up and sustain evidence-based practices? Excep. Children 79, 195-211. doi: 10.1177/001440291307900205

Lawrence, S., Smith, S., and Banerjee, R. (2016). Preschool Inclusion: Key Findings from Research and Implications for Policy. Child Care and Early Education Research Connections. New York, NY: National Center for Children in Poverty, Columbia University.

Love, H. R. (2018). Understanding High-Quality Inclusive Education Across Early Childhood Settings. Doctoral dissertation, University of Kansas, Lawrence, KS.

McLoughlin, J., and Stonehouse, A. (2006). Inclusion in Children's Services: Next Steps. Melbourne, Vic: Noah's Ark.

Meijer, C., Soriano, V., and Watkins, A. (2007). Inclusive education across Europe: reflections upon 10 years of work from the European Agency for Development in Special Needs Education. Childhood Educ. 83, 361-365. doi: 10.1080/00094056.2007.10522951

Melhuish, E. C. (2011). Preschool matters. Science 333, 299-300. doi: 10.1126/ science.1209459

Mingat, A., and Hoxha, E. (2010). The Development of Preschool in Albania: Perspectives, Policies and Costing. Dijon: UNICEF.

Moore, T. (2008). "Beyond the evidence: building universal early childhood services from the ground up," in Proceedings of the 8th National Conference, Centre for Child Community Health, (Sydney).

Odom, S. L., Brown, W. H., Frey, T., Karasu, N., Lee Smith-Canter, L., and Strain, P. S. (2003). Evidence-based practices for young children with autism: contributions for single-subject design research. Focus Autism Other Dev. Disabl. 18, 166-175. doi: 10.1177/10883576030180030401

Odom, S. L., Buysse, V., and Soukakou, E. (2011). Inclusion for young children with disabilities: a quarter century of research perspectives. J. Early Interv. 33, 344-356. doi: 10.1177/1053815111430094

Odom, S. L., Vitztum, J., Wolery, R., Lieber, J., Sandall, S., Hanson, M. J., et al. (2004). Preschool inclusion in the United States: a review of research from an ecological systems perspective. J. Res. Special Educ. Needs 4, 17-49. doi: 10.1111/J.1471-3802.2004.00016.x

Olusanya, B. O., Davis, A. C., Wertlieb, D., Boo, N. Y., Nair, M. K. C., Halpern, R., et al. (2018). Developmental disabilities among children younger than 5 years in 195 countries and territories, 1990-2016: a systematic analysis for the Global Burden of Disease Study 2016. Lancet Global Health 6, e1100-e1121.

Palsha, S. (2002). "An outstanding education for ALL children: learning from Reggio Emilia's approach to inclusion”, in Teaching and Learning Collaborative Exploration of the Reggio Emilia Approach, eds V. Fu, A. Stremmel, and L. Hill (Columbus, OH: Merrill), 109-129.

Peisner-Feinberg, E. S., Buysse, V., Benshoff, L., and Soukakou, E. (2011). "Recognition and response: response to intervention for pre-kindergarten," in Early Childhood Intervention: Shaping the Future for Children With Special 
Needs and Their Families, Vol. 3, eds C. Groark, S. M. Eidelman, L. Kaczmarek, and S. Maude (Santa Barbara, CA: Praeger), 37-53.

Rafferty, Y., and Griffin, K. W. (2005). Benefits and risks of reverse inclusion for preschoolers with and without disabilities: perspectives of parents and providers. J. Early Interv. 27, 173-192. doi: 10.1177/105381510502700305

Save the Children (2012). Inclusive Education in Albania- Analytical Study. Inclusive Education for Children with Disabilities. London: Save the Children.

Simeonsson, R. J. (2000). Early Childhood Development and Children with Disabilities in Developing Countries. Chapel Hill, NC: University of North Carolina.

Singer, G. H., Ethridge, B. L., and Aldana, S. I. (2007). Primary and secondary effects of parenting and stress management interventions for parents of children with developmental disabilities: a meta-analysis. Ment. Retard. Dev. Disabil. Res. Rev. 13, 357-369. doi: 10.1002/mrdd.20175

Snyder, P. A., Hemmeter, M. L., and Fox, L. (2015). Supporting implementation of evidence-based practices through practice-based coaching. Topics Early Childhood Special Educ. 35, 133-143. doi: 10.1177/0271121415594925

Staples, K. E., and Diliberto, J. A. (2010). Guidelines for successful parent involvement: working with parents of students with disabilities. Teach. Excep. Children 42, 58-63. doi: 10.1177/004005991004200607

Tahsini, I., Voko, K., Duci, V., and Hallkaj, E. D. (2014). Inclusion Practices in Albanian Preschools. Tirana: Save the Children.

Taylor, R., Richards, S., Goldstein, P., and Schilit, J. (1997). Teacher perceptions of inclusive settings. Teach. Excep. Children 29, 50-54. doi: 10.1177/ 004005999702900309

United Nations Educational, Scientific and Cultural Organization (2009). Policy Brief on Early Childhood. inclusion of Children with Disabilities: the Early Childhood Imperative. Paris: United Nations Educational, Scientific and Cultural Organization.

UNESCO (2020). COVID-19 Educational Disruption and Response. Available online at: https://en.unesco.org/covid19/educationresponse (accessed April 15, 2020).

Walker, S. P., Wachs, T. D., Grantham-McGregor, S., Black, M. M., Nelson, C. A., Huffman, S. L., et al. (2011). Inequality in early childhood: risk and protective factors for early child development. Lancet 378, 1325-1338. doi: 10.1016/S01406736(11)60555-2

Warren, S. R., Martinez, R. S., and Sortino, L. A. (2016). Exploring the quality indicators of a successful full-inclusion preschool program. J. Res. Childhood Educ. 30, 540-553. doi: 10.1080/02568543.2016.12 14651

Weiss, H., Caspe, M., and Lopez, M. E. (2006). Family Involvement in Early Childhood Education. Family Involvement Makes A Difference. Cambridge, MA: Harvard Family Research Project, 1-8.

Werner, E. E. (2000). "Protective factors and individual resilience," in Handbook of Early Childhood Intervention, 2nd Edn, eds J. P. Schonkoff and S. J. Meisels (New York, NY: Cambridge University Press), 115-132. doi: 10.1017/ cbo9780511529320.008

Wesley, P. W., and Buysse, V. (2010). "Changing times and the quest for quality," in The Quest for Quality: Promising Innovations for Early Childhood Programs, eds P. W. Wesley and V. Buysse (Baltimore, MD: Brookes), 1-19. doi: 10.4324/ 9781315170091-1

World Health Organization, and The United Nations Children's Fund (2012). Early Childhood Development and Disability: A Discussion Paper. Geneva: World Health Organization.

World Health Organization (2007). Early Childhood Development: A Powerful Equalizer. Geneva: World Health Organization.

Conflict of Interest: The authors declare that the research was conducted in the absence of any commercial or financial relationships that could be construed as a potential conflict of interest.

Copyright (๔) 2021 Hyseni Duraku, Jahiu, Likaj Shllaku, Boci and Shtylla. This is an open-access article distributed under the terms of the Creative Commons Attribution License (CC BY). The use, distribution or reproduction in other forums is permitted, provided the original author(s) and the copyright owner(s) are credited and that the original publication in this journal is cited, in accordance with accepted academic practice. No use, distribution or reproduction is permitted which does not comply with these terms. 